Article

\title{
Preparation of Sulfonated Poly(arylene ether nitrile)-Based Adsorbent as a Highly Selective and Efficient Adsorbent for Cationic Dyes
}

\author{
Xuefei Zhou, Penglun Zheng, Lingling Wang and Xiaobo Liu * \\ Research Branch of Advanced Functional Materials, School of Materials and Energy, University of Electronic \\ Science and Technology of China, Chengdu 61173, China; zhouxuefei0@hotmail.com (X.Z.); \\ 18482179228@163.com (P.Z.); wangll@std.uestc.edu.cn (L.W.) \\ * Correspondence: liuxb@uestc.edu.cn; Tel.: +86-28-83207326
}

Received: 21 November 2018; Accepted: 25 December 2018; Published: 26 December 2018

\begin{abstract}
In this work, a highly selective and efficient polymer adsorbent inspired by a water-soluble sulfonated poly(arylene ether nitrile) (SPEN) was successfully synthesized. Due to the distinct structure of functional carboxyl, sulfonic acid and rigid benzene rings, a facile aluminium (III) ions crosslinking method was employed to fabricate the SPEN-based adsorbents (SPEN-Al). Among the three adsorbents, SPEN-Al-2 exhibited superior adsorption capacities with uniform morphology. Subsequently, the SPEN-Al-2 was selected as the adsorbent for three cationic dyes (rhodamine B (Rh B), neutral red (NR), methylene blue (MB)) and three anionic dyes (orange G (OG), methyl orange (MO), acid fuchsin (AF)), respectively, demonstrating that the adsorbent possessing excellent selectivity toward cationic dyes. Moreover, the dye's adsorption selectivity of SPEN-Al-2 was further certificated in a binary cationic-anionic dyes mixtures (MB/OG and MB/MO) system. Taking MB as a dye model, a series of factors (contact time, concentration, temperature and $\mathrm{pH}$ ) and adsorption models were systematically investigated in dye adsorption experiments. Results indicated that the adsorption was endothermic and the maximum adsorption capacity of SPEN-Al-2 could reach up to $877.5 \mathrm{mg} / \mathrm{g}$; pseudo-second-model and Langmuir model were fitted to the adsorption kinetics and equilibrium isotherm, respectively, manifesting that SPEN-Al adsorbent was promising in the dyes removing field.
\end{abstract}

Keywords: sulfonated poly(arylene ether nitrile); aluminium ions; crosslinking; selective adsorption; cationic dyes

\section{Introduction}

In modern life, people have been accustomed to the world with gorgeous colors, which subsequently drive a steady growing quantity of dye industries varied in different fields such as textile, plastics, printing, food and leather industries [1,2]. However, the discharge of dye effluents into an aqueous ecosystem without prior treatment has brought about serious damages to the environment and human health. Though the polycyclic aromatic, heterocyclic structures in dyes contribute to their high stability to light, heat and catalytic agent, they also increase the toxicity and disposal difficulties of dyestuff wastewater [3-5]. Moreover, the co-existence of varied dyes in wastewater has made the treatment more intractable. Therefore, simple and effective dye treatment methods are in great demand to relieve environmental pressure. Numerous methods including ion exchange [6], membrane filtration [7], chemical coagulation/flocculation [8], microbial degradation [9], catalytic reduction [10], etc., have been developed for the treatment of dye-contaminated wastewater. However, these methods always suffer from high cost, complicated operation and generation of potential toxic byproduct [11]. 
By comparation, the adsorption method exhibited great strengths for wastewater treatment owing to its low energy consumption, high efficiency and ease of operation [12,13]. Moreover, the adsorption route will not produce toxic byproducts, for it is an accumulation process that occurs at the liquid-solid interface or gas-solid interface [14]. Generally, the adsorption includes two approaches, namely physisorption and chemisorption [15]. The physisorption is known as van der Waals adsorption, which is induced by the weak intermolecular forces of adsorbent and adsorbate, including van der Waals forces, hydrogen bonds, $\pi-\pi$ interaction, etc. $[16,17]$. However, physisorption not only requires an adsorbent with a specific surface morphology and porosity but also it needs to be unstable or unselective to dyes. For the chemisorption, it refers to the electrons exchange or transfer between adsorbent and adsorbate surfaces, resulting in the formation of stable chemical bonds between adsorbent and adsorbate $[18,19]$ with high adsorption efficiency. As a result, polymer-based adsorbents have drawn people's attention, since it is accessible to regulate their specific surface morphology and their functional groups (such as $-\mathrm{COOH},-\mathrm{SO}_{3} \mathrm{H},-\mathrm{NH}_{2},-\mathrm{OH}$ etc.), which is crucial for the adsorbent to interact with the targeted adsorbates in the dye removal process [20-22].

Poly(arylene ether nitrile) (PEN) is a kind of functional polymer that possesses a rigid aromatic backbone and adjustable side chains, and is famous for its excellent mechanical strength and light and heat stability [23]. After several decades of exploration, the nucleophilic substitution mechanism has developed to be the most mature strategy to synthesize a series of targeted PEN. Typically, a kind of poly(arylene ether nitrile)-containing pendant sulfonic acid group was named as sulfonated poly(arylene ether nitrile) (SPEN), and it has high water adsorption and ionization ability, as well as being considered to be a promising adsorbent candidate for the disposal of dyes wastewater [24]. It has been realized that the higher sulfonation degree is beneficial to ionization and adsorption of SPEN, while it may also result in excessive swelling or dissolution in aqueous solution [25]. Therefore, it was expected to develop a kind of highly efficient SPEN-based adsorbent that is applicable in an everchanging environment. Metallic crosslinking is a widely-accepted method to conquer these defects of SPEN, which are especially adaptable to polymeric adsorbent-containing functional ligands, such as $-\mathrm{COOH},-\mathrm{OH}$ [26-28]. In addition, the crosslinkers usually come from multivalent metal ions, such as $\mathrm{Ca}$ (II), $\mathrm{Al}$ (III), Fe (III), Zr (IV) [29,30]. For example, Assia Benhouria et al. have immobilized the alginate, bentonite and activated carbon together with $\mathrm{Ca}$ (II) ions and realized improved cationic dye removal efficiency according to the crosslinking mechanism [31].

In this work, a kind of SPEN-Al adsorbent was successfully prepared using a facile aluminium (III) $\left(\mathrm{Al}^{3+}\right)$ ions crosslinking method on the basis of a water-soluble sulfonated poly(arylene ether nitrile) (SPEN). The SPEN-Al-2 was certificated to possess the most uniform morphology and optimal dye-removing ability among the three SPEN-Al adsorbents, and it exhibited highly selective adsorption to cationic dyes, especially for methylene blue. Even for the binary dye mixtures that simultaneously contain cationic (methylene blue) and anionic (orange $\mathrm{G}$ or methyl orange) dyes, the selective adsorption ability of SPEN-Al for cationic dyes was still outstanding. Furthermore, a series of factors, including contact time, concentration, temperature and $\mathrm{pH}$, in the dye-removing process were conducted with the methylene blue (MB) as the dyes adsorption model. The results ascertained the equilibrium, kinetics and thermodynamics of the adsorption process, suggesting the SPEN-based adsorbent was highly efficient in selective adsorption for cationic dyes.

\section{Materials and Methods}

\subsection{Materials}

2,6-difluorobenzonitrile (DFBN) and potassium hydroquinone sulfonic acid potassium salt (SHQ) were supplied by Sigma Aldrich (Shanghai, China). Ethanol, phenolphthalein (PP), zinc (Zn), sodium hydroxide $(\mathrm{NaOH}, \mathrm{AR})$, aluminium chloride hexahydrate $\left(\mathrm{AlCl}_{3} \cdot 6 \mathrm{H}_{2} \mathrm{O}\right), \mathrm{N}$-methyl pyrrolidone (NMP, AR), toluene and tetrahydrofuran (THF), sodium dodecyl sulfate (SDS), dichloromethane $\left(\mathrm{CH}_{2} \mathrm{Cl}_{2}\right)$ and potassium carbonate $\left(\mathrm{K}_{2} \mathrm{CO}_{3}, \mathrm{AR}\right)$ were obtained from Chengdu Haihong Chemical Co. 
(Chengdu, China). Orange G (OG), methyl orange (MO), Acid fuchsin (AF), rhodamine B (Rh B), neutral red (NR) and methylene blue (MB) were received from Sinopharm chemical reagent (Shanghai, China). Phenolphthalin (PPL) was synthesized from phenolphthalein (PP), Zn and $\mathrm{NaOH}$ [25].

\subsection{Synthesis of SPEN}

In a typical synthesis procedure, a mixture of SHQ (20.429 g, $0.0896 \mathrm{~mol})$, PPL (12.223 g, $0.0384 \mathrm{~mol}), \mathrm{DFBN}(17.792 \mathrm{~g}, 0.128 \mathrm{~mol})$, NMP $(65 \mathrm{~mL})$ were added to the three-necked flask, followed by adding a catalyst of $\mathrm{K}_{2} \mathrm{CO}_{3}(30.515 \mathrm{~g})$ and dehydrating thr agent of toluene $(25 \mathrm{~mL})$, respectively. After a moderate mixing, the mixture was heated to $145^{\circ} \mathrm{C}$ and kept for $3 \mathrm{~h}$ to remove the generated water, and then the temperature was gradually heated to $155,165,175$, and $180{ }^{\circ} \mathrm{C}$ separately and maintained for $1 \mathrm{~h}$ [32]. Furthermore, the raw product was precipitated into ethanol, then it was washed with hot alcohol and deionized water to remove the unreacted reagents and solvent. The final product was dried in a vacuum oven at $80^{\circ} \mathrm{C}$ for $24 \mathrm{~h}$.

\subsection{Preparation of SPEN-Al Adsorbents}

The polymer adsorbents were prepared on the basis of our previous work with a slight modification [32]. Briefly, a given concentration of $\mathrm{Al}^{3+}$ was firstly prepared in $10 \mathrm{~mL}$ aqueous solution and then before being injected into the $20 \mathrm{~mL}$ SDS aqueous solution, $118 \mathrm{mg}$ SPEN was added into $1 \mathrm{~mL} \mathrm{CH} \mathrm{Cl}_{2}$ in companion with THF, then the two solutions were mixed together under vigorous stirring in a vial. After the continuous stirring for $24 \mathrm{~h}$, the evaporation of $\mathrm{CH}_{2} \mathrm{Cl}_{2}$ and THF helped the crosslinking between $\mathrm{Al}^{3+}$ and SPEN (SPEN-Al). The resultant polymeric adsorbent was washed with deionized water three times to remove the unreacted polymer and ions solution, and then the product was dried in vacuum oven at $60{ }^{\circ} \mathrm{C}$ for $48 \mathrm{~h}$. For the concentration of $\mathrm{Al}^{3+}$ varied from $0.05,0.10$ to $0.15 \mathrm{M}\left(5,10,15 \mathrm{wt} \%\right.$, weight ratio of $\left.\mathrm{AlCl}_{3} \cdot 6 \mathrm{H}_{2} \mathrm{O} / \mathrm{SPEN}\right)$, the obtained SPEN-Al were denoted as SPEN-Al-1, SPEN-Al-2, SPEN-Al-3 and their yields were calculated to be $42.3 \%, 92.7 \%$, $94.8 \%$, respectively. The diameter of irregular SPEN-Al-1 ranged from 50 to $250 \mathrm{~nm}$ and the obtained uniform SPEN-Al-2 possessed an average size of $80 \mathrm{~nm}$ scale, while a crosslinked net was obtained in SPEN-Al-3.

\subsection{Adsorption Experiments}

The batch adsorption experiments were conducted in a thermostat water bath with a magnetic stirrer. Typically, $10 \mathrm{mg}$ of SPEN-Al adsorbent was mixed with $40 \mathrm{~mL}$ of dye solution in a $50 \mathrm{~mL}$ vial, which then proceed the adsorption under continuous stirring at certain concentration of dye solution $\mathrm{pH}$ and temperature, etc. The adsorption performance of SPEN-Al toward anionic dyes (OG, MO, AF) and cationic dyes (Rh B, NR, MB) was firstly evaluated in neutral condition at $298.15 \mathrm{~K}$ with the dye concentration of $100 \mathrm{mg} / \mathrm{L}$. At certain time intervals, the supernatants were centrifuged at 10,000 rpm for $3 \mathrm{~min}$ and then analyzed by a ultraviolet-visible spectrophotometer (the maximum adsorption wavelength of OG, MO, AF, Rh B, NR and MB are located at ca. 475, 464, 547, 554, 532, and $664 \mathrm{~nm})$. Similarly, the binary dye mixtures containing cationic $\mathrm{MB}(40 \mathrm{mg} / \mathrm{L}, 20 \mathrm{~mL})$ and anionic OG $(40 \mathrm{mg} / \mathrm{L}, 20 \mathrm{~mL})$ or $\mathrm{MO}(40 \mathrm{mg} / \mathrm{L}, 20 \mathrm{~mL})$ were prepared, then SPEN-Al adsorbent was added in the mixture for further adsorption in the same condition as above. The dye removal efficiency $(R)$, instantaneous adsorption capacity $\left(q_{t}\right)$ and equilibrium adsorption capacity $\left(q_{e}\right)$ were calculated using the following Equations (1)-(3) [33]:

$$
\begin{aligned}
& R=\left(\frac{C_{o}-C_{e}}{C_{o}}\right) \times 100 \\
& q_{t}=\left(\frac{C_{o}-C_{t}}{m}\right) \times V
\end{aligned}
$$




$$
q_{e}=\left(\frac{C_{o}-C_{e}}{m}\right) \times V
$$

\subsection{Characterization}

The ultraviolet-visible (UV-vis) absorption spectra of SPEN and all the dyes in aqueous solution were detected with a UV-vis spectrophotometer (TU-1810, Persee, Beijing, China). The chemical structure of SPEN was recorded using a Bruker AV II-400 spectrometer, and the $1 \mathrm{H}$ NMR $(400 \mathrm{MHz})$ chemical shifts were measured relative to DMSO-d6 $(\mathrm{H}: \mathrm{d}=2.50 \mathrm{ppm})$ as the internal references. Fourier transform infrared (FT-IR) spectra of SPEN were obtained by a Shimadzu 8400S FTIR spectrometer. TGA-Q50 (TA Instruments, Newcastle, DE, USA) were involved in the thermal stability analysis of adsorbents, at a heating rate of $20{ }^{\circ} \mathrm{C} \mathrm{min}^{-1}$ under nitrogen flowing. Gel permeation chromatography (GPC) of SPEN was detected by Waters Breeze 2 HPLC system (Waters corporation, Milford, CT, USA), using DMF as eluent and poly(methyl methacrylate) as the standard. Morphology and microstructures were characterized by a scanning electron microscope (SEM) (JSM-6490LV, JEOL, Akishima, Japan). Zeta potentials were measured in aqueous solution using a Zeta PALS analyzer (Brookhaven Instruments Corporation, New York, NY, USA). A thermostat water bath (HJ-4B) and $\mathrm{pH}$ detector (AH 5201) were involved in the dyes removal experiments. The specific surface area of SPEN-Al was measured on NOVA 4000e adsorption apparatus (Quantachrome Instruments, Boynton Beach, FL, USA) and calculated by the Brunauer-Emmett-Teller (BET) method.

\section{Results and Discussion}

\subsection{Preparation of SPEN}

The synthesis of SPEN was based on nucleophilic substitution mechanism and the route was displayed in Figure 1A. The chemical structure of purified SPEN characterized with $1 \mathrm{H}$ NMR (DMSO-d6, $400 \mathrm{MHz}$ ) indicated that the characteristic peak at $6.69 \mathrm{ppm}$ belongs to tertiary hydrogen atoms in PPL; the hydrogen peaks on benzene rings range from 6.4 to $7.8 \mathrm{ppm}$, as shown in Figure S1. The functional groups of SPEN were further characterized with FTIR $\left(\mathrm{KBr}, \mathrm{cm}^{-1}\right): 2230(\mathrm{C} \equiv \mathrm{N})$, 1716 (-COO-), 1585-1454 (C=C of Ar), 1243 ( $\mathrm{Ar}-\mathrm{O}-\mathrm{Ar}), 1076-1018\left(\mathrm{~S}=\mathrm{O}\right.$ of $-\mathrm{SO}_{3}{ }^{-}$) (see Figure $\mathrm{S} 2$ ). Moreover, the average molecular weight $(\mathrm{Mn})$ and weight average molecular weight $(\mathrm{Mw})$ were 16303 and $20306 \mathrm{~g} \mathrm{~mol}^{-1}$, with a polydispersity (Mw/Mn) of 1.25. Besides, Figure 1B displayed the UV-Vis absorption spectra of SPEN in aqueous solution. The UV-Vis absorption peaks of SPEN at $308 \mathrm{~nm}$ proportionally increased when their concentrations increasing from $0.08 \mathrm{mg} / \mathrm{mL}$ to $0.01 \mathrm{~g} / \mathrm{mL}$. Moreover, a calibration curve mapping the absorption intensities $(\mathrm{Y})$ and concentrations $(\mathrm{X})$ was calculated as: $\mathrm{Y}=22.691 \mathrm{X}+0.03238$, with a high linear correlation coefficient of 0.99853 , suggesting that the pendent carboxyl and sulfonic acid groups endowed SPEN with absolute solubility in the aqueous solution.
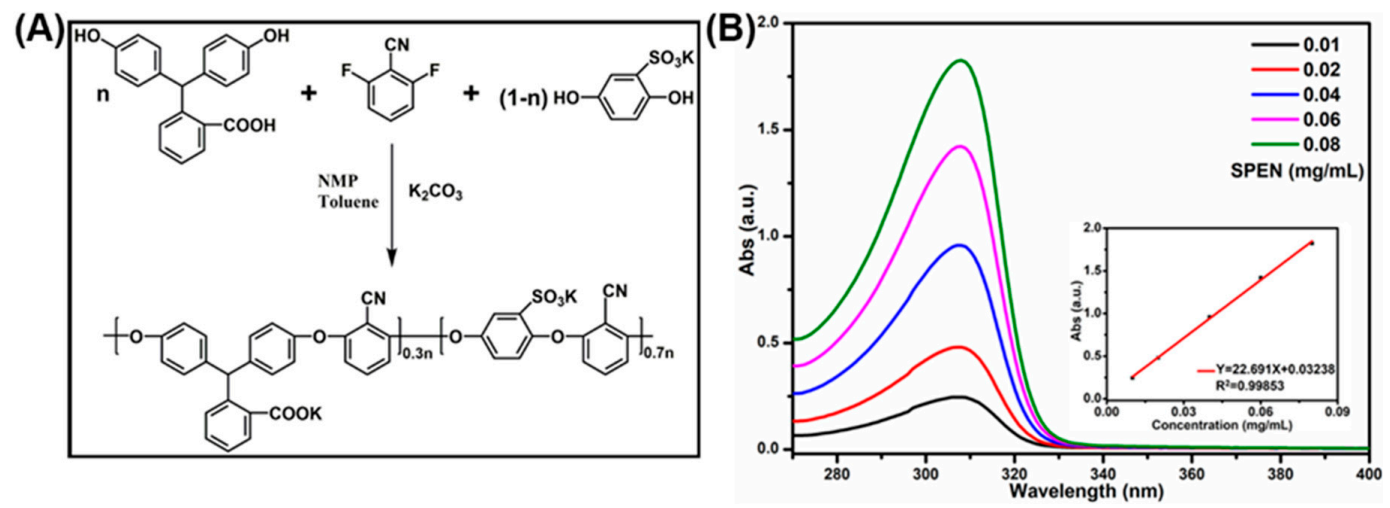

Figure 1. The synthesis route of SPEN and the UV-Vis absorption spectra of SPEN in aqueous solution at different concentrations. 


\subsection{Morphology Evolution}

Inspired by the high hydrophilia of sulfonic acid groups, the crosslinking ability of carboxyl and the rigid main skeleton of the benzene ring, the SPEN was considered to be a potential candidate in the dyes removing field. A self-assembling method was then developed to fabricate the SPEN-based adsorbent using the $\mathrm{Al}^{3+}$ as a crosslinker. The concentration of $\mathrm{Al}^{3+}$ was closely related with the $-\mathrm{COOH}$ content in the resulted SPEN adsorbent; three $\mathrm{Al}^{3+}$ in the concentration of $0.05,0.1$ and $0.15 \mathrm{M}$ were selected to crosslink SPEN. Based on the molecular weight of the monomeric unit of SPEN (about $366 \mathrm{~g} / \mathrm{mol}$ ) and the concentrations of $\mathrm{Al}^{3+}$, the molar ratio of $\mathrm{Al}^{3+}$ and $-\mathrm{COOH}$ were figured out to be 1:4.3, 1:2.15 and 1:1.433, respectively. The crosslinked SPEN-Al adsorbents were firstly characterized by a scanning electron microscope; the morphologic change of SPEN is shown in Figure 2. It is observed in Figure 2A that the raw SPEN without any $\mathrm{Al}^{3+}$ exhibits a flat interface. When the $\mathrm{Al}^{3+}$ with a concentration of $0.05 \mathrm{M}$ was involved in the system, the irregular SPEN-Al-1 with a diameter ranging from 50 to $250 \mathrm{~nm}$ is observed in Figure 2B. The ununiform structure may be attributed to the heterogeneous reaction between SPEN and $\mathrm{Al}^{3+}$, since the crosslinker was uncapable to interact with too much carboxyl groups simultaneously [34]. Besides, the low yield of SPEN-Al was calculated to be as low as $42.3 \%$, which was ascribed to the removal of a large proportion of un-crosslinked SPEN in the purification process. For comparison, the homogeneous SPEN-Al-2 adsorbent with an interconnected particle of $80 \mathrm{~nm}$ was achieved when the concentration of $\mathrm{Al}^{3+}$ increased to $0.10 \mathrm{M}$, as shown in Figure 2C. The yield of SPEN-Al-2 reached up to 92.7\%, indicating the high crosslinking efficiency between SPEN and $\mathrm{Al}^{3+}$. When the concentration of the crosslinker continue increased to $0.15 \mathrm{M}$, the obtained SPEN-Al-3 in Figure 2D displayed a crosslinked net with many spherical adsorbents precipitated on the crosslinked skeleton, and the yield of SPEN-Al-3 was calculated to be $94.8 \%$. It was speculated that the excessive crosslinker connected the initially formed SPEN-Al adsorbent and evolved into the polymer nets with the sphere adsorbent immobilized on it. The evolution of microscopic morphology confirmed that the $\mathrm{Al}^{3+}$ was capable of adjusting the morphologies of SPEN-Al.
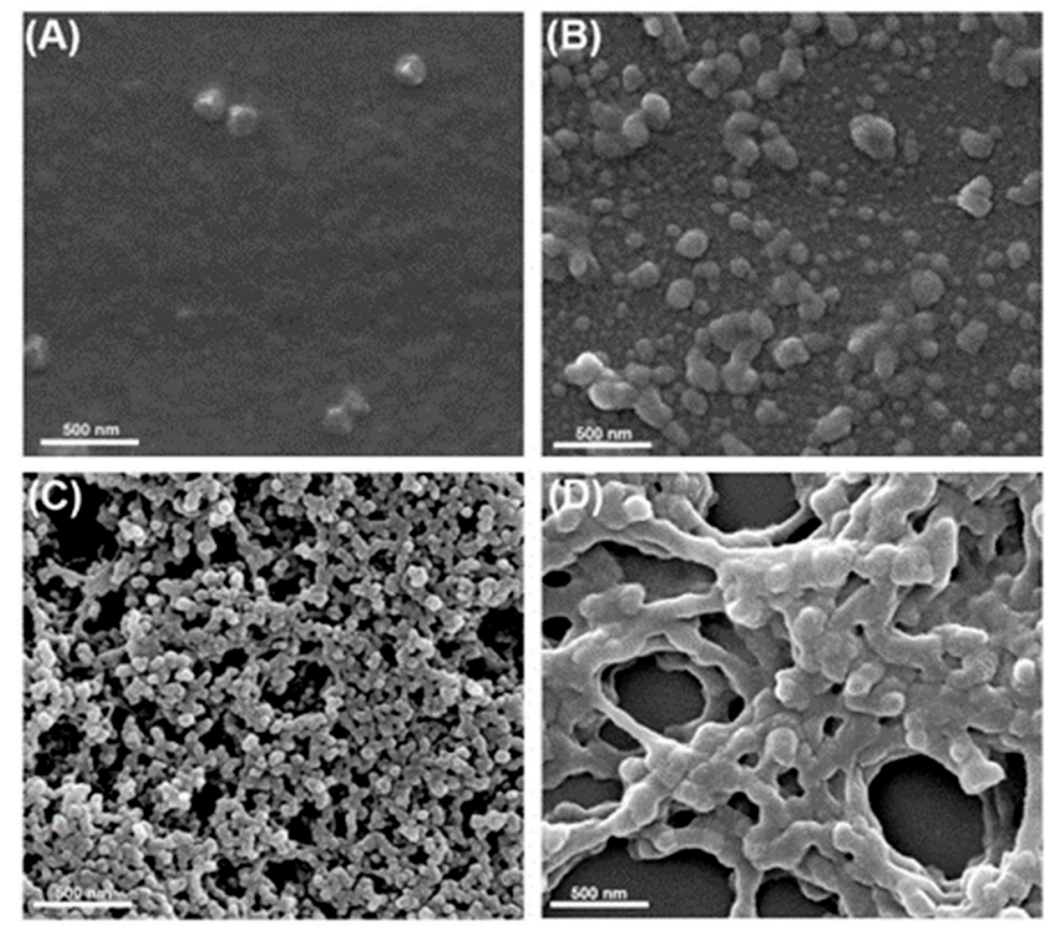

Figure 2. SEM images of SPEN before (A) and after crosslinking with $\mathrm{Al}^{3+}$ at different concentrations: (B) $0.05 \mathrm{M},(\mathbf{C}) 0.10 \mathrm{M}$ and (D) $0.15 \mathrm{M}$ in aqueous solution. 


\subsection{Thermal Stability}

The thermogravimetric characterizations were carried out to evaluate the stability of the as-prepared adsorbents. As the TGA curves show in Figure 3, the 5\% weight loss temperature of raw SPEN was located at $314^{\circ} \mathrm{C}$, which was mainly attributed to the decomposition of carboxyl and sulfonic acid [23]. In addition, the obvious weight loss of SPEN at $420^{\circ} \mathrm{C}$ corresponded to the decomposing of the benzene ring in the backbone. By comparison, the $5 \%$ weight loss temperatures of SPEN-Al continuously increased from 382 to $459^{\circ} \mathrm{C}$ along with the concentrations of the crosslinker increasing from 0.05 to $0.15 \mathrm{M}$, indicating that the crosslinking with $\mathrm{Al}^{3+}$ would improve the thermal stability of SPEN-based adsorbents. The improved thermal stability of SPEN-Al-3 also implied that the SPEN-Al-1 and SPEN-Al-2 still reserved unreacted functional groups, which would work in the subsequent dyes adsorption.

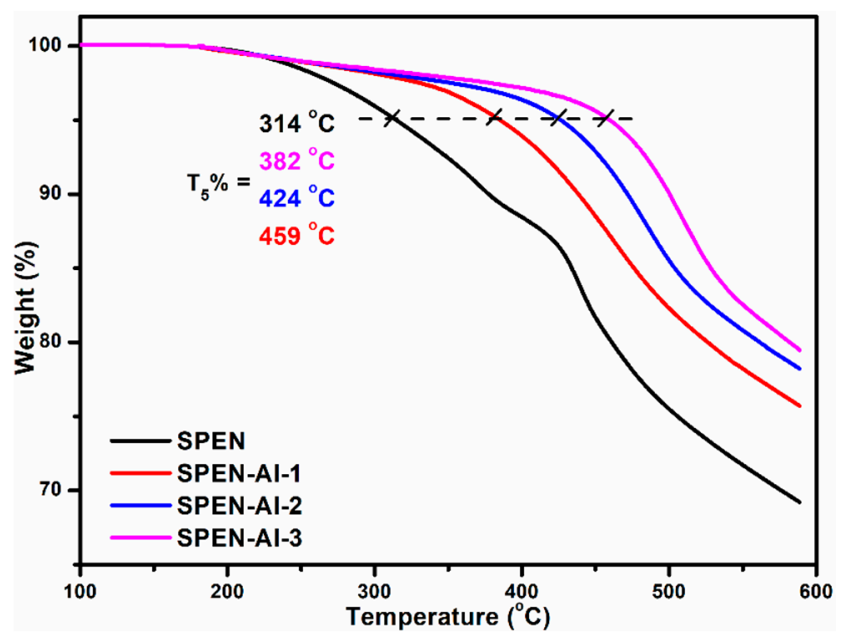

Figure 3. TGA curves of raw SPEN and SPEN-Al induced by $\mathrm{Al}^{3+}$ in different concentrations.

\subsection{Selective Adsorption for Dyes}

Next, three cationic dyes (Rh B, NR, MB) and three anionic dyes (OG, MO, AF) of the same concentration of $100 \mathrm{mg} / \mathrm{L}$ were applied to evaluate the adsorption performance of SPEN-Al at $298.15 \mathrm{~K}$, respectively. The results shown in Figure 4A display that the dye removal efficiency for cationic dyes of $\mathrm{Rh} \mathrm{B}, \mathrm{NR}$ and $\mathrm{MB}$ have reached $57.96 \%, 83.61 \%$ and $98.08 \%$ within $6 \mathrm{~h}$, respectively. The different dye removal efficiencies were closely related to the structure of the dyes. As shown in Figure $4 \mathrm{D}, \mathrm{MB}$ was a kind of phenothiazine salt containing dimethylamino, which would ionized in an alkaline type in aqueous solution; whereas the alkalescent NR was a kind of phenazine hydrochloride, whose ionization was restricted due to the presence of $\mathrm{HCl}$. Though the $\mathrm{Rh} \mathrm{B}$ was also a cationic dye due to the ionization of diethylin, the coexisting carboxyl prefered to repel the anionic SPEN-Al owing to like charges repelling each other. Furthermore, the molecular volume of the three dyes may also bring out the differences in their adsorption capacities. A smaller molecular volume would accelerate the dye's mobility and then promote it to interact with the adsorbent. In comparison with $\mathrm{MB}, \mathrm{NR}$ and $\mathrm{Rh} \mathrm{B}$, the largest volume of Rh B was consistent with its lowest adsorption efficiency. Therefore, the different adsorption selectivity of the SPEN-Al adsorbent for MB, Rh B and NR was induced by the ionization ability and molecular volume of dyes, resulting in the SPEN-Al adsorbent showing high selectivity for MB compared to RhB and NR. 


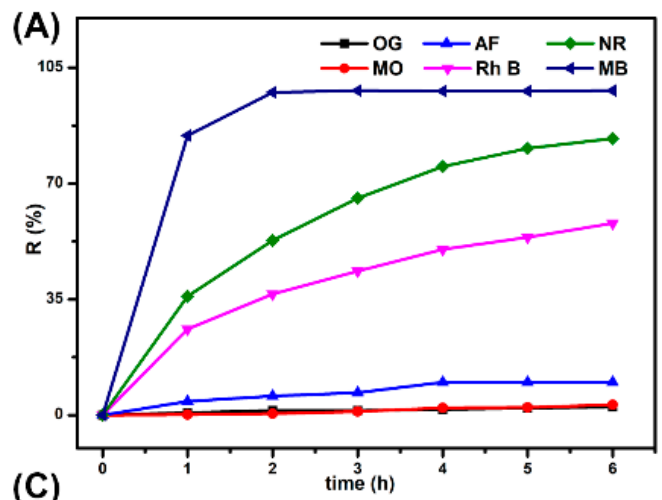

(C)

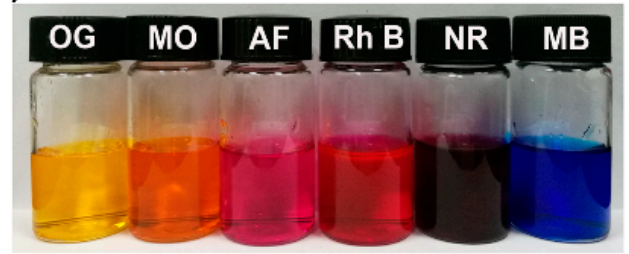

Before adsorption

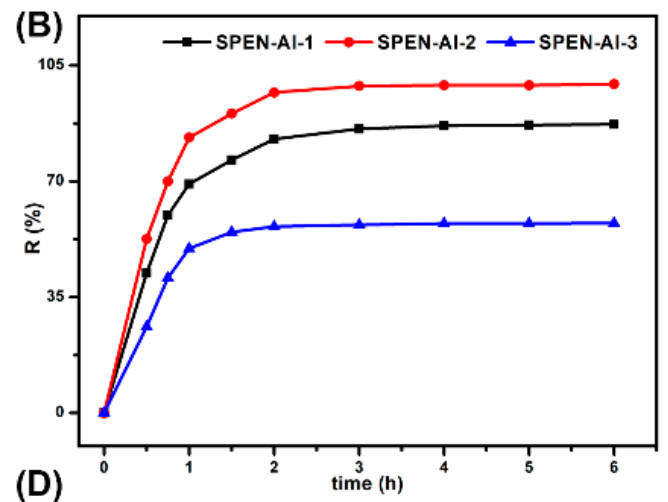

(D)

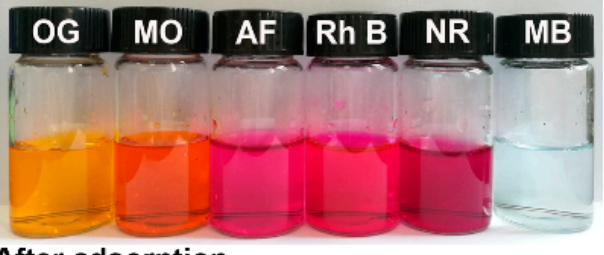

After adsorption

$(\mathrm{E})$

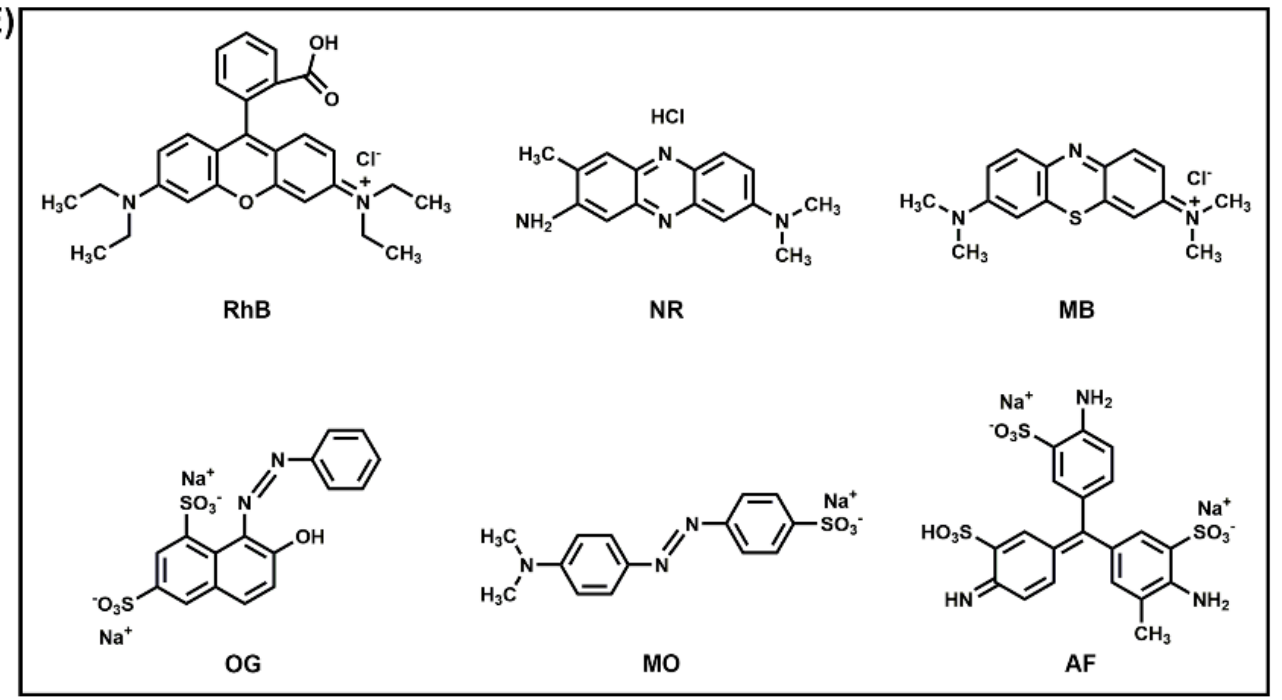

Figure 4. Effect of contact time on the removal efficiency of six dyes by the certain SPEN-Al-2 adsorbent (A) and the removal efficiency of MB by three different SPEN-Al adsorbents (B). Digital photos of the organic dyes in aqueous solutions before (C) and after (D) adsorption by SPEN-Al-2. Chemical structures of organic dyes (Rh B, NR, MB, OG, MO and AF) selected for adsorbent (E).

The SPEN-Al almost makes no sense to anionic dyes, as their absorbances changed very little as the images show in Figure $4 C, D$, respectively. Besides, the variations of the absorption intensity in the dye-removal process were detected by UV-vis spectrophotometer, respectively, as shown in Figure S3. The vast adsorption difference for anionic and cationic dyes indicated that the electrostatic interaction may be the main force in the dye's adsorption process. This is because SPEN-Al adsorbent was negatively charged owing to the ionization of $-\mathrm{COOK}$ and $-\mathrm{SO}_{3} \mathrm{~K}$, which made it attractive to cationic dyes and repulsive to anionic dyes. To select the optimal absorbent, three kinds of SPEN-Al were applied in the adsorption for MB $(100 \mathrm{mg} / \mathrm{L}, 40 \mathrm{~mL})$ at $298.15 \mathrm{~K}$, respectively. The results displayed in Figure 4B show that the dyes adsorption efficiency of SPEN-Al-1, SPEN-Al-2 and SPEN-Al-3 were $87.23 \%, 98.08 \%$ and $57.34 \%$, respectively. When it comes to SPEN-Al-1 with a low yield of $42.3 \%$, long-time adsorption would cause its dissolution in dye solution and give rise to low adsorption efficiency. As for SPEN-Al-3, the excessive $\mathrm{Al}^{3+}$ would consume a large quantity of the active sites in the adsorbent, resulting in a crosslinked net morphology (Figure 2D) and low 
dye adsorption efficiency. Obviously, the uniform SPEN-Al-2 which originated from moderate $\mathrm{Al}^{3+}$ concentration was optimum for dye adsorption.

The nitrogen adsorption-desorption isotherm of the SPEN-Al-2 obtained at $77 \mathrm{~K}$ is exhibited in Figure S4, which indicated that the specific surface area of the adsorbent was about $4.18 \mathrm{~m}^{2} \mathrm{~g}^{-1}$. The isotherm plot of SPEN-Al-2 was classified to type III with a hysteresis loop in the relative pressure range of $0.9-1.0$, suggesting that the physical interaction between the adsorbent and nitrogen was weak. Apart from cationic dyes in the one-component solution, the dyes mixtures (MB/OG and MB/MO) that simultaneously contain cationic dye (MB) and anionic dye (OG or $\mathrm{MO}$ ) were also prepared to explore the adsorption selectivity of SPEN-Al-2. As shown in Figure 5A,B, the characteristic absorption peak of MB at $664 \mathrm{~nm}$ continuously decreased after adding SPEN-Al-2, while the other absorption peaks of OG at $475 \mathrm{~nm}$ or $\mathrm{MO}$ at $464 \mathrm{~nm}$ remained almost unchanged. As the inset shown in Figure 5A, the color of the mixture dyes containing $\mathrm{MB} / \mathrm{OG}$ varied from turquoise to orange yellow while the $\mathrm{MB}$ was not observed. The color change indicated that the MB was removed by SPEN-Al-2 but the $\mathrm{MO}$ was left. Similarly, the inset of Figure $5 \mathrm{~B}$ also presents the color changes of MB/MO dye mixture from olive drab to golden yellow with the help of SPEN-Al-2, suggesting the selective adsorption of SPEN-Al-2 to cationic MB dye. In addition, the dye removal efficiency of MB in MB/OG and MB/MO dye mixtures were respectively calculated to be $95.4 \%$ and $97.5 \%$ within $120 \mathrm{~min}$, respectively, as shown in Figure 5C,D. The different dye removing efficiencies in MB/OG and MB/MO systems were highly dependent on the anionic groups of $\mathrm{OG}$ and $\mathrm{MO}$, respectively. Comparing the anionic dyes of OG and MO, it was found that an OG molecular has two sulfo groups while a MO molecular only possesses one sulfo group. The stronger repulsive interaction between OG and SPEN-Al in the MB/OG system was considered to hinder the removal of $\mathrm{MB}$ more obviously than the repulsive interaction in $\mathrm{MB} / \mathrm{MO}$ system. These results certified that the SPEN-Al-2 adsorbent maintained adsorption ability to cationic MB dye even in the binary dyes mixture, thus the MB was selected as the dye model to systematically investigate the adsorption behavior of SPEN-Al.
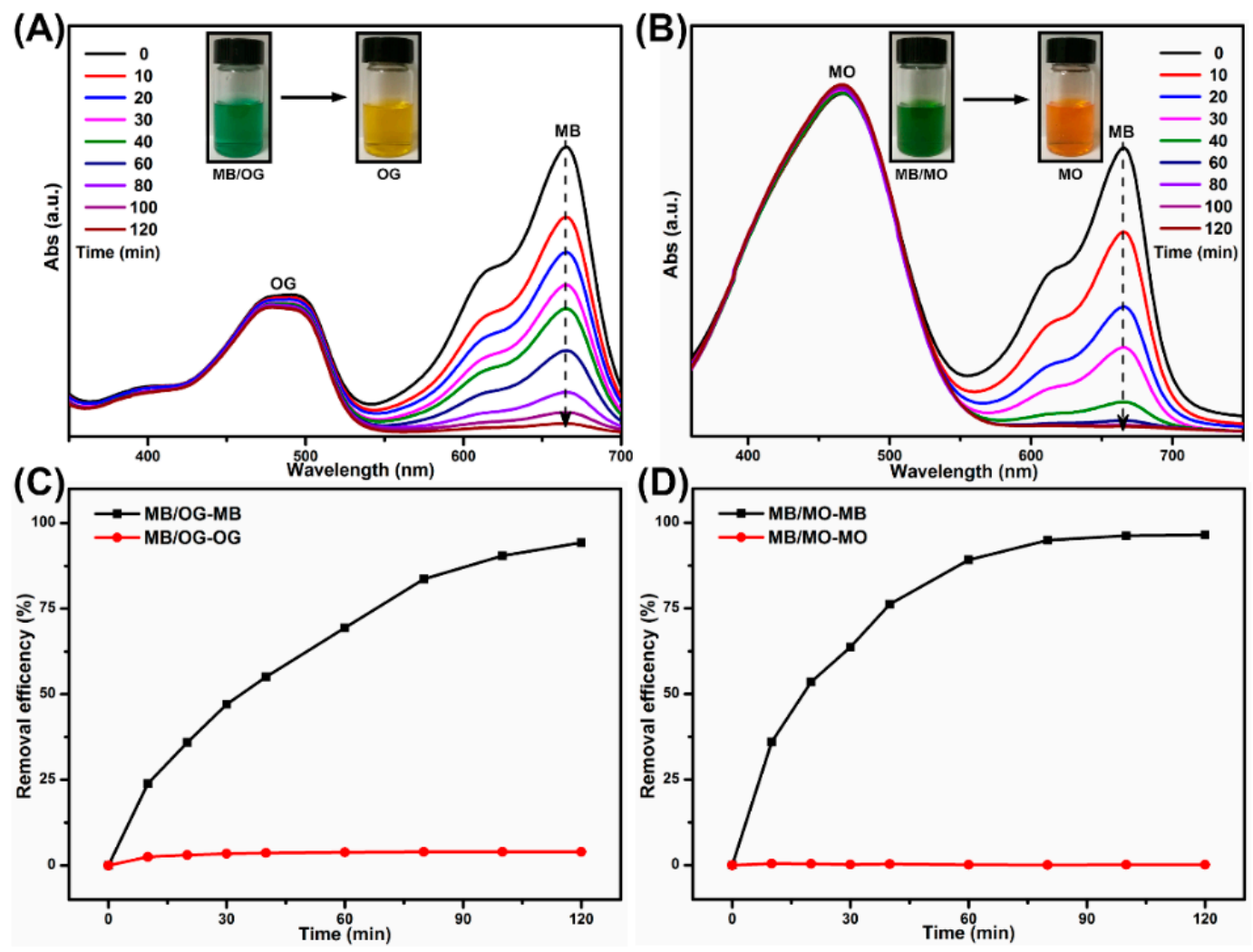

Figure 5. The UV-vis spectra and the corresponding removal efficiency of MB/OG mixture (A) (C) and $\mathrm{MB} / \mathrm{MO}$ mixture (B) (D) onto SPEN-Al-2 at different contact times. 


\subsection{Effect of Initial Solution $p H$}

Since the variation of $\mathrm{pH}$ was closely related to the ionization of the adsorbent and adsorbate, the effects of $\mathrm{pH}$ were investigated to evaluate the adsorption performance of SPEN-Al-2. To study the effect of $\mathrm{pH}, 10 \mathrm{mg}$ of SPEN-Al was mixed with $40 \mathrm{~mL}$ of $\mathrm{MB}(300 \mathrm{mg} / \mathrm{L})$ in the condition of $298.15 \mathrm{~K}$ and different initial $\mathrm{pH}$; the contact time was fixed to be $12 \mathrm{~h}$. The initial $\mathrm{pH}$ of $\mathrm{MB}$ ranging from 2 to 10 was regulated by $1.0 \mathrm{~mol} / \mathrm{L} \mathrm{NaOH}$ and $1.0 \mathrm{~mol} / \mathrm{L} \mathrm{HCl}$ aqueous solution. As shown in Figure 6A, the adsorption capacity presented an intense increase from 690.95 to $821.07 \mathrm{mg} / \mathrm{g}$ with the $\mathrm{pH}$ of MB solutions having increased from 7 to 10 , while it decreased to $277.19 \mathrm{mg} / \mathrm{g}$ at a pH of 2 . On the other hand, the zeta potential of SPEN-Al-2 dispersed in aqueous solution was detected. Results indicated the SPEN-Al-2 were negatively charged, and the zeta potential presented a decreased trend along with the increase of $\mathrm{pH}$, as shown in Figure 6B, suggesting the high original ionization ability of SPEN-Al-2. The zeta potential manifested that alkaline solutions would contribute to the ionization of $\mathrm{MB}$ and activated the positively-charged groups on SPEN-Al-2, which subsequently would enhance the electrostatic interaction between the adsorbent and adsorbate, resulting in an increased adsorption capacity [35]. The acidic environment tended to restrict the ionization of carboxyl radicals and sulfonic radicals of SPEN-Al-2, which would bring in not only the electrostatic repulsion between SPEN-Al-2 and $\mathrm{MB}$ but also the competitive adsorption between $\mathrm{H}^{+}$ions and cationic $\mathrm{MB}$, resulting in a decreased adsorption capactity [33].
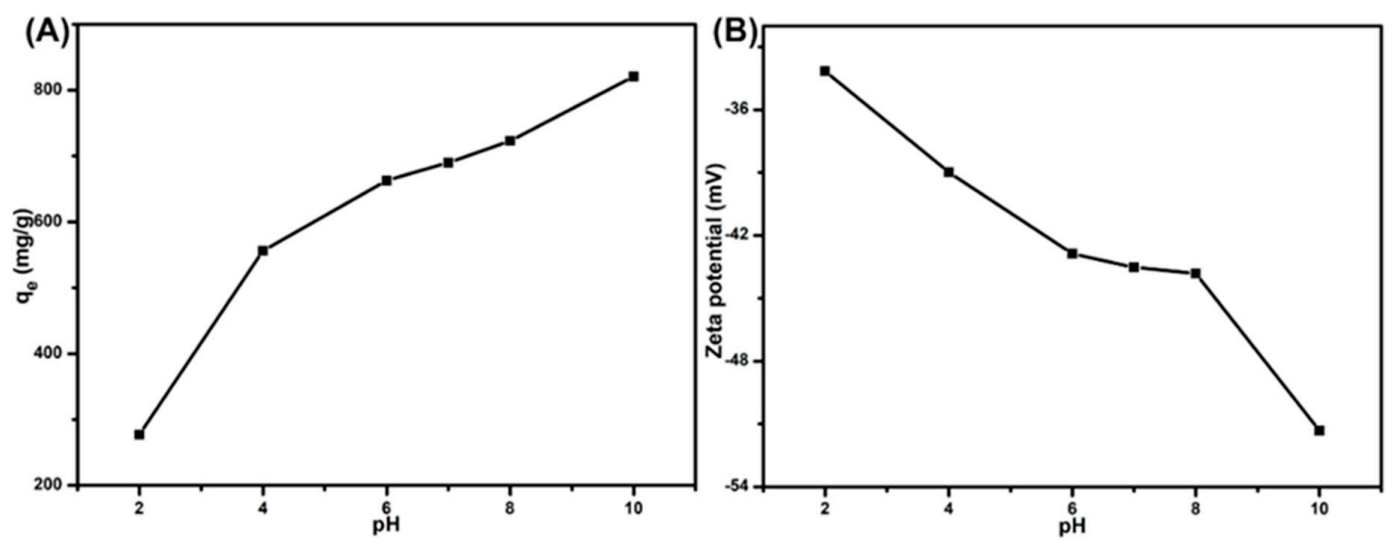

Figure 6. The effect of solution $\mathrm{pH}$ on the adsorption of MB onto the SPEN-Al-2 (A). Tthe variation of zeta potentials of SPEN-Al-2 versus the solution $\mathrm{pH}(\mathbf{B})$.

\subsection{Adsorption Kinetics}

As the results show in Figure 7A, the SPEN-Al-2 gave increased equilibrium adsorption capacities in two MB solutions ( 50 and $70 \mathrm{mg} / \mathrm{L}$ ), since the initial MB concentrations can provide a driving force to overcome the mass transfer resistance of the dye. It was clear that both the two curves presented a fast increase at the initial time and then they slowed down to get the balanced state, reaching the adsorption equilibrium within $180 \mathrm{~min}$. The drastic changes may be closely related with the available sites on the surface of SPEN-Al-2. At the beginning, the MB molecules rapidly occupied the empty sites on SPEN-Al adsorbent, resulting in a drastic increase in the adsorption curves. After the full occupation of valuable sites, the SPEN-Al-2 was not available for any anionic MB, resulting in the platform in the graph. The kinetics of dye adsorption is one of the main preconditions in selecting the operational environment. To elaborate the dye's adsorption behavior, three conventional models that are denoted as pseudo-first order, pseudo-second order and intraparticle diffusion models have been widely accepted; these formulas are described as following Equations (4) and (5) [12]:

$$
q_{t}=q_{e}\left(1-e^{-k_{1} t}\right)
$$




$$
q_{t}=\frac{k_{2} q_{e}^{2} t}{1+k_{2} q_{e} t}
$$

where $k_{1}\left(\mathrm{~min}^{-1}\right)$ and $k_{2}\left(\mathrm{~g} \mathrm{mg}^{-1} \mathrm{~min}^{-1}\right)$ are the rate constants of pseudo-first-order and pseudo-second-order adsorption, respectively; $t(\mathrm{~min})$ is the contact time.
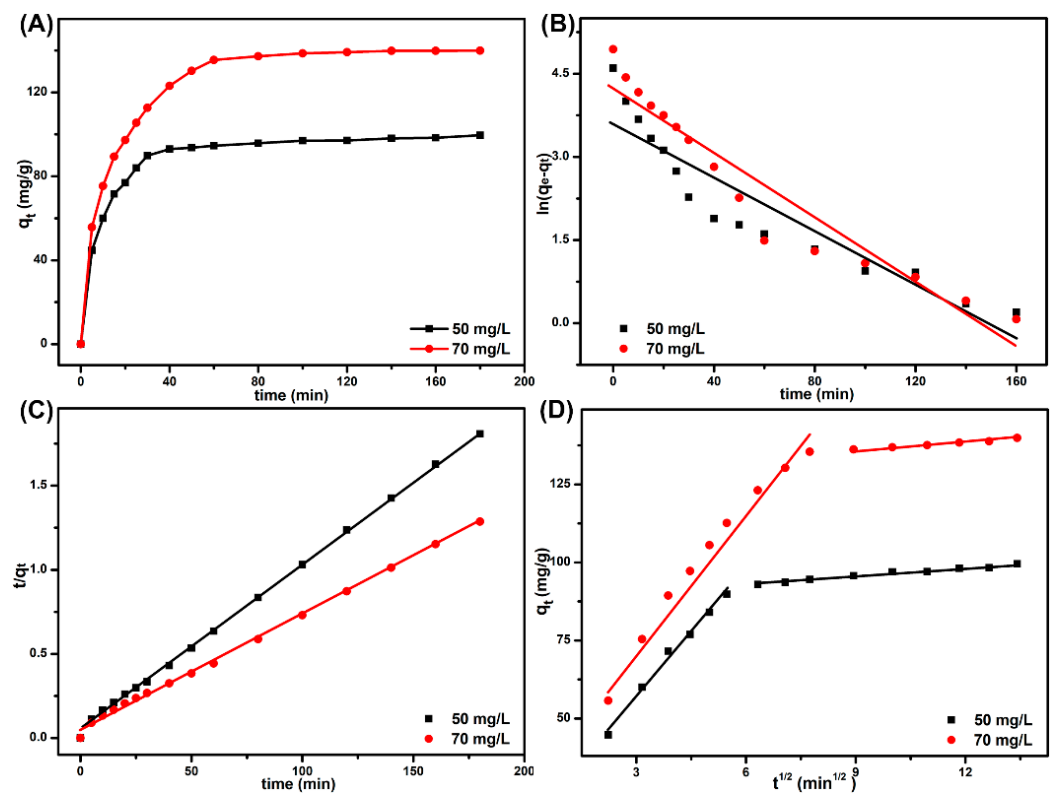

Figure 7. Effect of contact time on $\mathrm{MB}$ adsorption capacity (A), pseudo-first-order (B), pseudo-second-order (C) and intraparticle diffusion (D) for the adsorption of MB onto SPEN-Al-2.

Based on Figure 7A, the corresponding linear regression equations were calculated and displayed in Figure $7 \mathrm{~B}, \mathrm{C}$, respectively. Moreover, the kinetic parameters of the correlation coefficient $\left(R^{2}\right), k_{1}, k_{2}$ and calculated $q_{e}$ (cal.) are exhibited in Table 1. It was observed that the linear regression equations from the two MB solutions (50 and $70 \mathrm{mg} / \mathrm{L}$ ) followed the same adsorption kinetics. Taking the adsorption of $50 \mathrm{mg} / \mathrm{L}$ MB for example, the $R^{2}(0.8543)$ calculated from pseudo-first-order was much lower than $R^{2}$ (0.9992) of pseudo-second-order. Moreover, the adsorption capacity calculated from the pseudo-second-order $(102.04 \mathrm{mg} / \mathrm{g}$ ) was close to the experimental results $(99.539 \mathrm{mg} / \mathrm{g})$. In summary, the adsorption of MB onto SPEN-Al-2 belonged to pseudo-second-order, which corresponds with the assumption that the adsorption rate was mainly controlled by chemical adsorption.

Table 1. The kinetic parameters of adsorption of MB onto SPEN-Al-2.

\begin{tabular}{cccc}
\hline $\mathbf{C}_{\mathbf{0}}(\mathbf{m g} / \mathrm{L})$ & Parameters & $\mathbf{5 0}$ & $\mathbf{7 0}$ \\
\hline Pseudo-first-order & $k_{1}\left(\mathrm{~min}^{-1}\right)$ & 0.0244 & 0.0296 \\
& $q_{e}(\mathrm{cal}).(\mathrm{mg} / \mathrm{g})$ & 35.701 & 69.650 \\
& $q_{e}(\mathrm{exp}).(\mathrm{mg} / \mathrm{g})$ & 99.539 & 139.88 \\
& $R^{2}$ & 0.8543 & 0.9166 \\
\hline Pseudo-second-order & $k_{2}(\mathrm{~g} / \mathrm{mg} \mathrm{min})$ & 0.0020 & 0.0010 \\
& $q_{e}(\mathrm{cal}).(\mathrm{mg} / \mathrm{g})$ & 102.04 & 145.77 \\
& $q_{e}(\mathrm{exp})(\mathrm{mg} / \mathrm{g})$ & 99.539 & 139.88 \\
& $R^{2}$ & 0.9992 & 0.9981 \\
\hline Intraparticle diffusion & $k_{i 1}$ & 13.704 & 14.286 \\
& $C$ & 15.853 & 30.739 \\
& $R_{1}{ }^{2}$ & 0.9890 & 0.9725 \\
& $k_{i 2}$ & 0.8832 & 0.7909 \\
& $C$ & 87.589 & 129.03 \\
& $R_{2}{ }^{2}$ & 0.9795 & 0.9811 \\
\hline
\end{tabular}


Generally, the adsorption occurred in several steps; the process was usually studied using the intraparticle diffusion model, as the following Equation (6) exhibits [14]:

$$
q_{t}=k_{i} t^{0.5}+C
$$

where $k_{i}\left(\mathrm{mg} \mathrm{g}^{-1} \mathrm{~min}^{-0.5}\right)$ is the intraparticle diffusion rate constant and $C\left(\mathrm{mg} \mathrm{g}^{-1}\right)$ is a constant that can be used to evaluate the effect of boundary layer thickness. Similarly, the linear regression equations were also calculated on the basis of Figure 7A. As for the adsorption of MB with a concentration of $50 \mathrm{mg} / \mathrm{L}$, the two separated linear equations in Figure 7D suggested that the adsorption of MB onto SPEN-Al-2 needs two steps. The first step of adsorption belonged to film diffusion, namely the MB transport from the aqueous solution to the surface of SPEN-Al-2. The second step was the interparticle diffusion, which was attributed to the rough surface and interior of SPEN-Al-2. That the value of $\mathrm{k}_{\mathrm{i} 1}$ was much higher than $\mathrm{k}_{\mathrm{i} 2}$ indicated the intraparticle diffusion was a gradual process. Moreover, the high value of $C$ implied that the intraparticle diffusion was not the rate-limiting step and the film diffusion was important in the MB adsorption process.

\subsection{Adsorption Isotherm}

The adsorption isotherm is another significant model that helps to explain the interacting behavior between the adsorbent and adsorbate. The experiments were performed in different concentrations (100-700 mg/L) of MB solution at $298.15 \mathrm{~K}$ in a neutral environment. The experimental equilibrium data of MB adsorption onto SPEN-Al-2 are fitted to Langmuir (Figure 8A) and Freundlich (Figure 8B) models, which are defined as the following Equations (7) and (8) [36]:

$$
\begin{gathered}
\frac{C_{e}}{q_{t}}=\frac{1}{K_{L} q_{m}}+\frac{C_{e}}{q_{m}} \\
\ln q_{e}=\ln K_{F}+\frac{1}{n} \ln C_{e}
\end{gathered}
$$

where $K_{L}(\mathrm{~L} / \mathrm{mg})$ is the Langmuir adsorption equilibrium constant and $q_{m}$ is the maximum adsorption capacity $(\mathrm{mg} / \mathrm{g}) . K_{F}$ and $\mathrm{n}$ are Freundlich constants. The Langmuir model is applicable to monolayer adsorption with homogeneous active sites on the surface of the adsorbent [37]. To the contrary, the Freundlich adsorption model is suitable for heterogeneous adsorption, because the available sites on the adsorbent are inconsistent [38]. As the isotherms in Figure 8 and adsorption isotherm constants in Table 2 show, the adsorption isotherm was fitted to the Langmuir model, because $R^{2}(0.99952)$ of the Langmuir model was close to 1 and larger than $R^{2}$ (0.75912) of the Freundlich model. In addition, the maximum adsorption capacity $(704.28 \mathrm{mg})$ of SPEN-Al-2 calculated from the Langmuir model was also close to the experimental date $(690.95 \mathrm{mg} / \mathrm{g})$, and the molar ratio of adsorbed MB and anion units in SPEN-Al-2 in the equilibrium state was calculated to be 1:1.135. Similarly, on the basis of the maximum adsorption capacity of SPEN-Al-1 (639 mg/g) and SPEN-Al-3 (352 mg/g), the molar ratio of the cationic MB and anion units on SPEN-Al were calculated to be 1:0.763 and 1:1.313, respectively. It is suggested that SPEN-Al-2-containing homogeneous active sites and adsorption follow the Langmuir model. What is more, a separation factor related with the Langmuir model denoted as $R_{L}$ was applied to evaluate the type of adsorption and the relation was displayed as below [36]:

$$
R_{L}=\frac{1}{1+K_{L} C_{o}}
$$

With the initial concentration of $C_{0}(\mathrm{mg} / \mathrm{L})$ and Langmuir constant $K_{L}(\mathrm{~L} / \mathrm{mg})$ in mind, the $R_{L}$ was calculated in the range of 0.02708 to 0.00396 , indicating that the MB adsorption on SPEN-Al-2 was favorable. Because the value of $R_{L}$ represented the isotherm was either irreversible $\left(R_{L}=0\right)$, favorable $\left(0<R_{L}<1\right)$, linear $\left(R_{L}=1\right)$ or unfavorable $\left(R_{L}>1\right)$ [36]. 

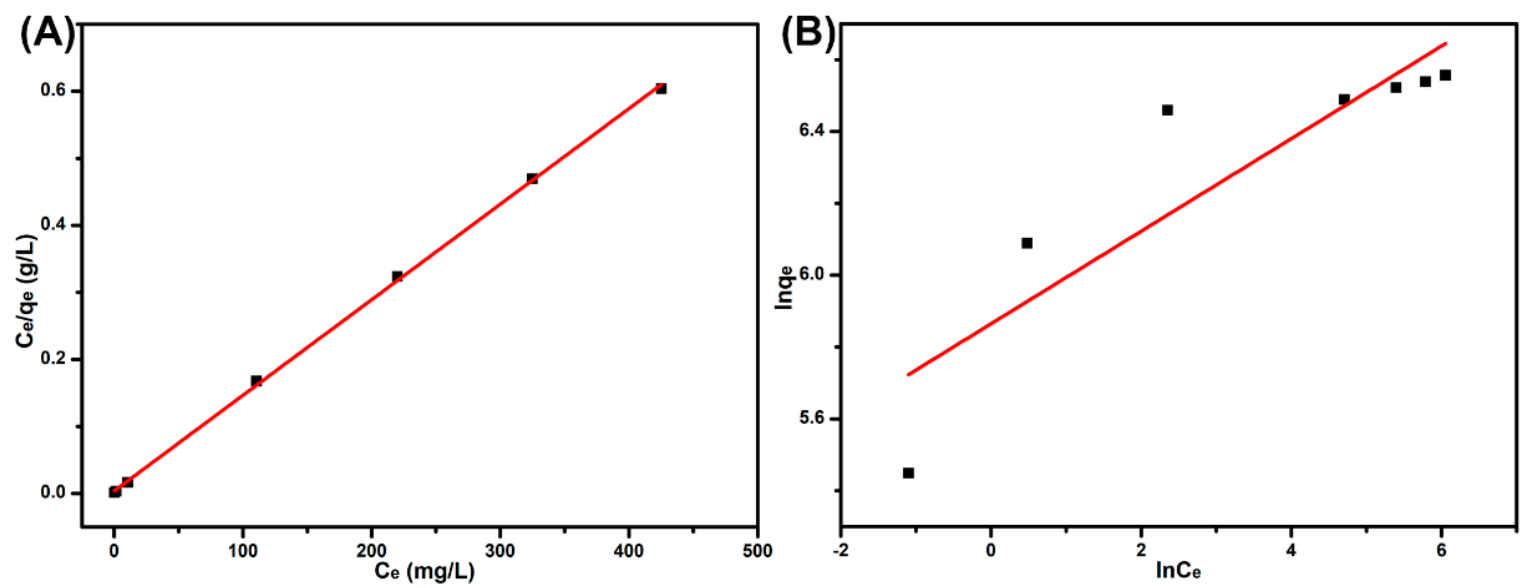

Figure 8. Langmuir isotherm (A) and Freundlich isotherm (B) for the adsorption of MB onto SPEN-Al-2.

Table 2. Adsorption isotherm constants for the adsorption of MB onto SPEN-Al-2.

\begin{tabular}{ccc}
\hline Isotherms & \multicolumn{2}{c}{ Parameters (Temperature $=\mathbf{2 9 8 . 1 5} \mathbf{K})$} \\
\hline Langmuir & $q_{m}(\mathrm{mg} / \mathrm{g})$ & 699.301 \\
& $K_{L}(\mathrm{~L} / \mathrm{mg})$ & 0.35930 \\
& $R_{L}$ & 0.01373 \\
$R^{2}$ & 0.99952 \\
\hline Freundlich & $K_{F}\left[(\mathrm{mg} / \mathrm{g})(\mathrm{L} / \mathrm{mg})^{1 / \mathrm{n}}\right]$ & 15.9420 \\
& $n^{-1}$ & 0.12896 \\
& $R^{2}$ & 0.75912 \\
\hline
\end{tabular}

\subsection{Adsorption Thermodynamics}

The thermodynamic analyses were conducted by using $10 \mathrm{mg}$ of SPEN-Al and $40 \mathrm{~mL}$ of MB solution $(300 \mathrm{mg} / \mathrm{L})$ in neutral condition. Figure $9 \mathrm{~A}$ presents the different equilibrium adsorption capacities of SPEN-Al-2 to MB at five different temperatures. The adsorption capacity increased from $594.2 \mathrm{mg} / \mathrm{g}$ at $288.15 \mathrm{~K}$ to $877.5 \mathrm{mg} / \mathrm{g}$ at $328.15 \mathrm{~K}$, which implied that the MB adsorption on SPEN-Al-2 was an endothermic reaction. To explore the internal energy changes in the dye adsorption process, the thermodynamic models calculated from Gibbs free energy change $\left(\Delta G^{o}\right)$, enthalpy change $\left(\Delta H^{o}\right)$ and entropy change $\left(\Delta S^{o}\right)$ are defined as the following Equations (10) and (11):

$$
\begin{gathered}
\Delta G^{o}=-R T \ln K_{c} \\
\ln K_{c}=-\frac{\Delta H^{o}}{R T}+\frac{\Delta S^{o}}{R}
\end{gathered}
$$

where $R$ and $T$ are the universal gas constant $(8.314 \mathrm{~J} / \mathrm{mol} \mathrm{K})$ and the system temperature $(K)$, $K_{c}\left(q_{e} / C_{e}\right)$ represent the Langmuir equilibrium constant $(\mathrm{L} / \mathrm{mol})$. The thermodynamic model and related parameters are exhibited in Figure $9 \mathrm{~B}$ and Table 3. Results indicated that the negative value of $\Delta G^{o}$ gradually decreased from $-7.879 \mathrm{KJ} / \mathrm{mol}$ at $288.15 \mathrm{~K}$ to $-11.998 \mathrm{KJ} / \mathrm{mol}$ at $328.15 \mathrm{~K}$, confirming the adsorption process was spontaneous and more favorable at high temperature [39]. The positive value of $\Delta H^{o}$ also suggested the adsorption was an endothermic reaction, which is consistent with the result from Figure 9A. In addition, the positive value of $\Delta S^{o}$ manifested in the enhanced randomness at the solid-solute interface, for the rising temperature has promoted the mobility of dye molecules and increased the number of active sites in the adsorption process [40]. 

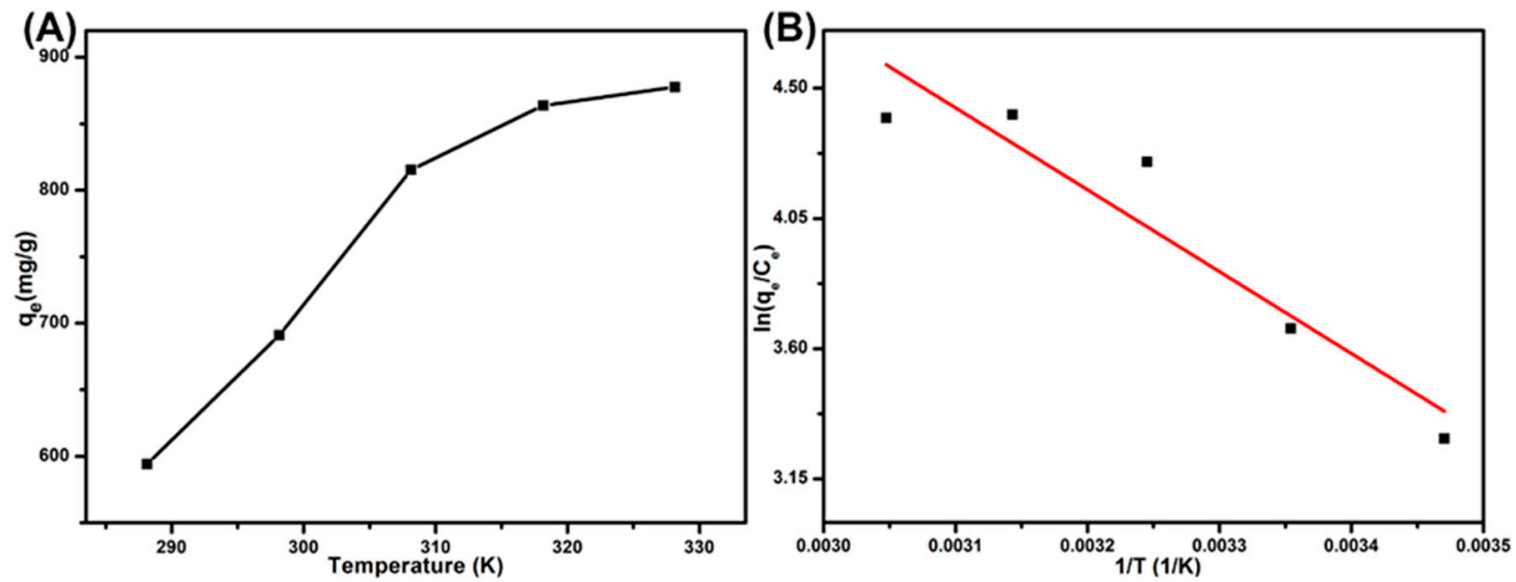

Figure 9. The effect of temperature on the adsorption of MB onto SPEN-Al-2 (A) and thermodynamic parameters for the adsorption of MB onto SPEN-Al-2 (B).

Table 3. Thermodynamic constants of the adsorption of MB onto SPEN-Al-2.

\begin{tabular}{ccccc}
\hline \multirow{T}{*}{$(\mathrm{K})$} & \multicolumn{4}{c}{ Thermodynamic Parameters } \\
\cline { 2 - 5 } & $\ln \boldsymbol{\Delta}$ & $\boldsymbol{\Delta} \boldsymbol{G}^{\mathbf{0}} \mathbf{( \mathrm { KJ } / \mathbf { m o l } )}$ & $\boldsymbol{\Delta} \boldsymbol{S}^{\mathbf{0}}(\mathbf{J} /(\mathbf{m o l ~ K})$ & $\left.\Delta \boldsymbol{H}^{\mathbf{0}} \mathbf{( K J} / \mathbf{m o l}\right)$ \\
\hline 288.15 & 3.289 & -7.879 & 109.78 & 23.527 \\
298.15 & 3.669 & -9.095 & & \\
308.15 & 4.245 & -10.877 & & \\
318.15 & 4.409 & -11.662 & & \\
328.15 & 4.398 & -11.998 & & \\
\hline
\end{tabular}

\subsection{Adsorption Mechanism}

The FTIR spectra of MB, SPEN-Al-2 and MB-loaded SPEN-Al-2 are conducted and studied to gain insight into the adsorption mechanism, as displayed in Figure 10. The characteristic adsorption bands of MB at 2921 and $2854 \mathrm{~cm}^{-1}$ belonged to $\mathrm{C}-\mathrm{H}$ symmetric and asymmetric stretching vibrations of methyl; the band located at $1610 \mathrm{~cm}^{-1}$ corresponded to $C=C$ skeletal vibrations of the benzene ring, as shown in Figure 10A. Compared with virgin SPEN in Figure S2, the spectra of SPEN-Al in Figure 10B exhibited a weakened absorption peak of -COO- at $1716 \mathrm{~cm}^{-1}$ after crosslinking with $\mathrm{Al}^{3+}$. Besides, the FTIR spectra of MB-loaded SPEN-Al-2 demonstrated new absorption bands at 2921 and $2854 \mathrm{~cm}^{-1}$, in which the bands were consistent with the $\mathrm{C}-\mathrm{H}$ symmetric and asymmetric stretching vibrations of methyl on the MB molecule, indicating the MB was indeed adsorbed onto SPEN-Al-2. Moreover, the characteristic absorption band of $-\mathrm{COO}-$ at $1716 \mathrm{~cm}^{-1}$ disappeared and the $\mathrm{S}=\mathrm{O}$ at 1076 and $1018 \mathrm{~cm}^{-1}$ were weakened, which is owing to the electrostatic interaction between anionic SPEN-Al-2 with cationic MB. Specifically, the negatively-charged -COO- and $-\mathrm{SO}_{3}{ }^{-}$on SPEN-Al-2 supplied plenty of active sites for the electrostatic interaction with positively-charged MB. There was also a slight shift of the absorption band of $C=C$ skeletal vibrations varying from $1598 \mathrm{~cm}^{-1}$ to $1600 \mathrm{~cm}^{-1}$, indicating the weak $\pi-\pi$ interaction between SPEN-Al and MB. Therefore, the high selectivity and adsorption capacity of SPEN-Al-2 would be mainly attributed to the electrostatic interaction, $\pi-\pi$ interaction and specific surface morphology between SPEN-Al-2 and cationic MB. 


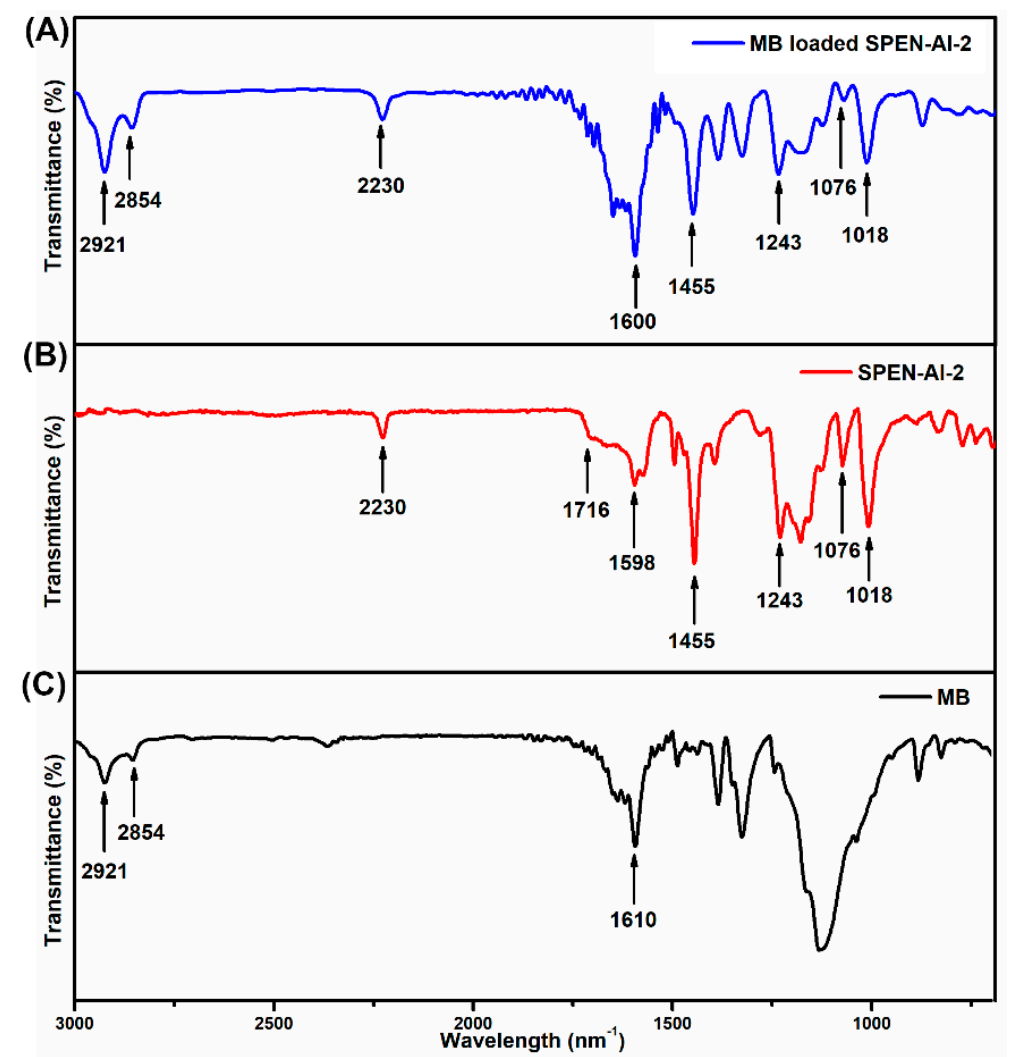

Figure 10. FTIR spectra of MB and SPEN-Al-2 before and after adsorption of MB.

\section{Conclusions}

In conclusion, a new polymeric adsorbent was developed by a facile crosslinking method with $\mathrm{Al}^{3+}$ and it proved to be a highly selective and efficient adsorbent for cationic dyes. Originating from the crosslinking ability of the pendent carboxyl groups on SPEN, the optimal adsorbent of SPEN-Al-2 prepared using $0.1 \mathrm{M} \mathrm{Al}^{3+}$ was found to possess excellent stability and dye-removing ability. Moreover, the SPEN-Al-2 presented high adsorption selectivity to cationic dyes (MB, NR, $\mathrm{Rh} B$ ), to which selectivity was also applicable in the binary cationic-anionic dye mixtures (MB/OG and $\mathrm{MB} / \mathrm{MO}$ ) system. Results indicated that the higher $\mathrm{pH}$ value, concentration or temperature were all in favor of the adsorption for cationic MB, and the maximum adsorption capacity of SPEN-Al-2 towards $\mathrm{MB}$ could reach up to $877.5 \mathrm{mg} / \mathrm{g}$ at $328.15 \mathrm{~K}$ in neutral environment. The high adsorption capacity can be mainly ascribed to the electrostatic interactions and the structure property of SPEN-Al-2 adsorbent.

The kinetic studies demonstrated that the adsorption included two diffusion steps and was fitted to a pseudo-second-order kinetic model. The Langmuir model elaborated that the SPEN-Al-2 have homogeneous active sites, and thermodynamic analysis certified that the MB adsorption was a spontaneous as well as endothermic reaction. It is expected that the series of SPEN-based adsorbents will be explored for dye adsorption from the dye effluents.

Supplementary Materials: The following are available online at http:/ /www.mdpi.com/2073-4360/11/1/32/s1, Figure S1: The 1H NMR of SPEN. Figure S2: The FTIR of SPEN. Figure S3: The UV-Vis spectra of different dyes: orange $G(A)$, methyl orange (B), acid fuchsin (C), rhodamine B (D), neutral red (E) and methylene blue (F) adsorption onto SPEN-Al at specific time intervals, respectively. Figure S4. Nitrogen adsorption-desorption isotherm for the SPEN-Al adsorbent.

Author Contributions: Conceptualization and writing-original draft preparation, X.Z.; methodology, X.Z. and P.Z.; investigation, X.Z and L.W.; data curation, L.W.; review and editing, P.Z; validation and funding acquisition, X.L.

Funding: This research was funded by Natural Science Foundation of China, grant number is 51773028 and 51603029. 
Acknowledgments: The authors wish to thank the financial support to this work provided by the Natural Science Foundation of China (No. 51773028, 51803020).

Conflicts of Interest: The authors declare no conflict of interest.

\section{References}

1. Holkar, C.R.; Jadhav, A.J.; Pinjari, D.V.; Mahamuni, N.M.; Pandit, A.B. A critical review on textile wastewater treatments: Possible approaches. J. Environ. Manag. 2016, 182, 351-366. [CrossRef] [PubMed]

2. Molina, E.F.; Parreira, R.L.; De Faria, E.H.; de Carvalho, H.W.; Caramori, G.F.; Coimbra, D.F.; Nassar, E.J.; Ciuffi, K.J. Ureasil-poly(ethylene oxide) hybrid matrix for selective adsorption and separation of dyes from water. Langmuir 2014, 30, 3857-3868. [CrossRef] [PubMed]

3. Qiu, J.; Feng, Y.; Zhang, X.; Jia, M.; Yao, J. Acid-promoted synthesis of UiO-66 for highly selective adsorption of anionic dyes: Adsorption performance and mechanisms. J. Colloid Interface Sci. 2017, 499, 151-158. [CrossRef] [PubMed]

4. Gupta, V.K.; Suhas. Application of low-cost adsorbents for dye removal-A review. J. Environ. Manag. 2009, 90, 2313-2342. [CrossRef] [PubMed]

5. Blachnio, M.; Budnyak, T.M.; Derylo-Marczewska, A.; Marczewski, A.W.; Tertykh, V.A. Chitosan-Silica Hybrid Composites for Removal of Sulfonated Azo Dyes from Aqueous Solutions. Langmuir 2018, 34, $2258-2273$. [CrossRef] [PubMed]

6. Wu, J.-S.; Liu, C.-H.; Chu, K.H.; Suen, S.-Y. Removal of cationic dye methyl violet 2B from water by cation exchange membranes. J. Membr. Sci. 2008, 309, 239-245. [CrossRef]

7. Liu, C.; Cheng, L.; Zhao, Y.; Zhu, L. Interfacially crosslinked composite porous membranes for ultrafast removal of anionic dyes from water through permeating adsorption. J. Hazard Mater. 2017, 337, $217-225$. [CrossRef]

8. Verma, A.K.; Dash, R.R.; Bhunia, P. A review on chemical coagulation/flocculation technologies for removal of colour from textile wastewaters. J. Environ. Manag. 2012, 93, 154-168. [CrossRef]

9. Solís, M.; Solís, A.; Pérez, H.I.; Manjarrez, N.; Flores, M. Microbial decolouration of azo dyes: A review. Process Biochem. 2012, 47, 1723-1748. [CrossRef]

10. Li, F.; Dong, Y.; Kang, W.; Cheng, B.; Cui, G. Enhanced removal of azo dye using modified PAN nanofibrous membrane Fe complexes with adsorption/visible-driven photocatalysis bifunctional roles. Appl. Surf. Sci. 2017, 404, 206-215. [CrossRef]

11. Liu, L.; Gao, Z.Y.; Su, X.P.; Chen, X.; Jiang, L.; Yao, J.M. Adsorption Removal of Dyes from Single and Binary Solutions Using a Cellulose-based Bioadsorbent. ACS Sustain. Chem. Eng. 2015, 3, 432-442. [CrossRef]

12. Liu, L.; Gao, Y.; Zhao, J.; Yuan, L.; Li, C.; Liu, Z.; Hou, Z. A Mild Method for Surface-Grafting PEG Onto Segmented Poly (Ester-Urethane) Film with High Grafting Density for Biomedical Purpose. Polymers 2018, 10, 1125. [CrossRef]

13. Lyu, W.; Yu, M.; Feng, J.; Yan, W. Highly crystalline polyaniline nanofibers coating with low-cost biomass for easy separation and high efficient removal of anionic dye ARG from aqueous solution. Appl. Surf. Sci. 2018, 458, 413-424. [CrossRef]

14. Haldorai, Y.; Shim, J.-J. An efficient removal of methyl orange dye from aqueous solution by adsorption onto chitosan/MgO composite: A novel reusable adsorbent. Appl. Surf. Sci. 2014, 292, 447-453. [CrossRef]

15. Yagub, M.T.; Sen, T.K.; Afroze, S.; Ang, H.M. Dye and its removal from aqueous solution by adsorption: A review. Adv. Colloid Interface Sci. 2014, 209, 172-184. [CrossRef] [PubMed]

16. Wang, Z.; Wei, R.; Gu, J.; Liu, H.; Liu, C.; Luo, C.; Kong, J.; Shao, Q.; Wang, N.; Guo, Z.; et al. Ultralight, highly compressible and fire-retardant graphene aerogel with self-adjustable electromagnetic wave absorption. Carbon 2018, 139, 1126-1135. [CrossRef]

17. Alaba, P.A.; Oladoja, N.A.; Sani, Y.M.; Ayodele, O.B.; Mohammed, I.Y.; Olupinla, S.F.; Daud, W.M.W. Insigh into wastewater decontamination using polymeric adsorbents. J. Environ. Chem. Eng. 2018, 6, 1651-1672. [CrossRef]

18. Huang, Q.; Liu, M.; Chen, J.; Wan, Q.; Tian, J.; Huang, L.; Jiang, R.; Wen, Y.; Zhang, X.; Wei, Y. Facile preparation of MoS 2 based polymer composites via mussel inspired chemistry and their high efficiency for removal of organic dyes. Appl. Surf. Sci. 2017, 419, 35-44. [CrossRef] 
19. Zhang, R.Z.; Quan, S.; Xia, M.; Wang, Q.; Zhang, W.; Yang, J.M. Effect of surface charge status of amorphous porous coordination polymer particles on the adsorption of organic dyes from an aqueous solution. J. Colloid Interface Sci. 2018, 525, 54-61. [CrossRef] [PubMed]

20. Wei, R.; Wang, J.; Zhang, H.; Han, W.; Liu, X. Crosslinked polyarylene ether nitrile interpenetrating with zinc ion bridged graphene sheet and carbon nanotube network. Polymers 2017, 9, 342. [CrossRef]

21. Wei, R.; Song, W.; Yang, F.; Zhou, J.; Zhang, M.; Zhang, X.; Zhao, W.; Zhao, C. Bidirectionally pH-Responsive Zwitterionic Polymer Hydrogels with Switchable Selective Adsorption Capacities for Anionic and Cationic Dyes. Ind. Eng. Chem. Res. 2018, 57, 8209-8219. [CrossRef]

22. Seo, M.; Kim, S.; Oh, J.; Kim, S.J.; Hillmyer, M.A. Hierarchically porous polymers from hyper-cross-linked block polymer precursors. J. Am. Chem. Soc. 2015, 137, 600-603. [CrossRef] [PubMed]

23. Zheng, P.; Liu, J.; Liu, X.; Jia, K. Cross-linked sulfonated poly(arylene ether nitrile)s with high selectivity for proton exchange membranes. Solid State Ion. 2017, 303, 126-131. [CrossRef]

24. Feng, M.; Huang, Y.; Cheng, Y.; Liu, J.; Liu, X. Rational design of sulfonated poly(ether ether ketone) grafted graphene oxide-based composites for proton exchange membranes with enhanced performance. Polymer 2018, 144, 7-17. [CrossRef]

25. Zheng, P.; Xu, M.; Liu, X.; Jia, K. Sulfonated poly(arylene ether nitrile)s containing cross-linkable nitrile groups for proton exchange membranes. Solid State Ion. 2018, 316, 110-117. [CrossRef]

26. Feng, J.; Zhu, J.; Lv, W.; Li, J.; Yan, W. Effect of hydroxyl group of carboxylic acids on the adsorption of Acid Red $\mathrm{G}$ and Methylene Blue on $\mathrm{TiO}_{2}$. Chem. Eng. J. 2015, 269, 316-322. [CrossRef]

27. Wei, R.; Tu, L.; You, Y.; Zhan, C.; Wang, Y.; Liu, X. Fabrication of crosslinked single-component polyarylene ether nitrile composite with enhanced dielectric properties. Polymer 2018, 161, 162-169. [CrossRef]

28. Satilmis, B.; Budd, P.M. Selective dye adsorption by chemically-modified and thermally-treated polymers of intrinsic microporosity. J. Colloid Interface Sci. 2017, 492, 81-91. [CrossRef]

29. Kang, D.; Liu, Q.; Chen, M.; Gu, J.; Zhang, D. Spontaneous Cross-linking for Fabrication of Nanohybrids Embedded with Size-Controllable Particles. ACS Nano 2016, 10, 889-898. [CrossRef]

30. Zhou, X.; Jia, K.; He, X.; Wei, S.; Wang, P.; Liu, X. Assembly of carboxylated zinc phthalocyanine with gold nanoparticle for colorimetric detection of calcium ion. J. Mater. Sci. Mater. Electron. 2018, 29, 8380-8389. [CrossRef]

31. Benhouria, A.; Islam, M.A.; Zaghouane-Boudiaf, H.; Boutahala, M.; Hameed, B.H. Calcium alginate-bentonite-activated carbon composite beads as highly effective adsorbent for methylene blue. Chem. Eng. J. 2015, 270, 621-630. [CrossRef]

32. Zhou, X.; Jia, K.; He, X.; Wei, S.; Wang, P.; Liu, X. Microemulsion self-assembling of novel amphiphilic block co-polyarylene ether nitriles and photosensitizer $\mathrm{ZnPc}$ towards hybrid superparticles for photocatalytic degradation of Rhodamine, B. Mater. Chem. Phys. 2018, 207, 212-220. [CrossRef]

33. Fu, J.; Chen, Z.; Wang, M.; Liu, S.; Zhang, J.; Zhang, J.; Han, R.; Xu, Q. Adsorption of methylene blue by a high-efficiency adsorbent (polydopamine microspheres): Kinetics, isotherm, thermodynamics and mechanism analysis. Chem. Eng. J. 2015, 259, 53-61. [CrossRef]

34. Hara, Y.; Kanamori, K.; Morisato, K.; Miyamoto, R.; Nakanishi, K. Iron(iii) oxyhydroxide and oxide monoliths with controlled multiscale porosity: Synthesis and their adsorption performance. J. Mater. Chem. A 2018, 6, 9041-9048. [CrossRef]

35. Li, X.; Zhou, M.; Jia, J.; Jia, Q. A water-insoluble viologen-based $\beta$-cyclodextrin polymer for selective adsorption toward anionic dyes. React. Funct. Polym. 2018, 126, 20-26. [CrossRef]

36. Zhao, J.; Huang, Q.; Liu, M.; Dai, Y.; Chen, J.; Huang, H.; Wen, Y.; Zhu, X.; Zhang, X.; Wei, Y. Synthesis of functionalized MgAl-layered double hydroxides via modified mussel inspired chemistry and their application in organic dye adsorption. J. Colloid Interface Sci. 2017, 505, 168-177. [CrossRef]

37. Fu, J.; Xin, Q.; Wu, X.; Chen, Z.; Yan, Y.; Liu, S.; Wang, M.; Xu, Q. Selective adsorption and separation of organic dyes from aqueous solution on polydopamine microspheres. J. Colloid Interface Sci. 2016, 461, 292-304. [CrossRef]

38. Wan, X.; Zhan, Y.; Long, Z.; Zeng, G.; He, Y. Core@double-shell structured magnetic halloysite nanotube nano-hybrid as efficient recyclable adsorbent for methylene blue removal. Chem. Eng. J. 2017, 330, 491-504. [CrossRef] 
39. Huang, W.; Xu, J.; Lu, D.; Deng, J.; Shi, G.; Zhou, T. Rational design of magnetic infinite coordination polymer core-shell nanoparticles as recyclable adsorbents for selective removal of anionic dyes from colored wastewater. Appl. Surf. Sci. 2018, 462, 453-465. [CrossRef]

40. Zhao, Y.; Chen, Y.; Zhao, J.; Tong, Z.; Jin, S. Preparation of SA-g-(PAA-co-PDMC) polyampholytic superabsorbent polymer and its application to the anionic dye adsorption removal from effluents. Sep. Purif. Technol. 2017, 188, 329-340. [CrossRef]

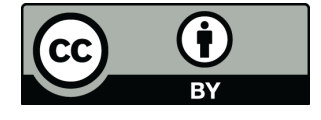

(C) 2018 by the authors. Licensee MDPI, Basel, Switzerland. This article is an open access article distributed under the terms and conditions of the Creative Commons Attribution (CC BY) license (http:/ / creativecommons.org/licenses/by/4.0/). 